\title{
Crear o copiar... ¿Cuál es la diferencia?
}

\author{
Ricardo López P1,2,a. \\ Create or copy... \\ Which is the difference?
}

Creating and copying are two different processes; we must not confuse creativity with plagiarism. However, this distinction is problematic, because there is no possibility of creating from scratch, this implies that any creative act necessarily arises from accumulative experience, inevitably producing a continuity between old and new. Even so it is necessary to establish clearly the difference between creating and copying. It is not desirable that a matter of such importance remains in the nebula or that the relationship between creativity and ethics is kept unaware. There are many cases of plagiarism, but this cannot be a consolation. There is no gain when the existence of a plagiarism is ignored or concealed and less when it is unjustified (Rev Méd Chile 2009; 137: 121-6).

(Key words: Ethics; Manuscripts; Plagiarism)

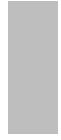

Recibido el 20 de agosto, 2008. Aceptado el 26 de septiembre, 2008.

${ }^{1}$ Facultad de Psicología, Universidad Diego Portales. ${ }^{2}$ Departamento de Educación en Ciencias de la Salud, Facultad de Medicina, Universidad de Chile. Santiago de Chile.

aDoctor en Filosofía

"En un lugar de la Mancha de cuyo nombre no quiero acordarme, frente al pelotón de fusilamiento, el coronel Aureliano Buendía había de recordar aquella tarde en que, al despertar de un sueño agitado, Gregorio Samsa se encontró en su cama transformado en un horrible insecto".

Copyright. Jorge Maronna y Luís María Pescetti

$\mathrm{P}$ lagio es el acto de apropiación de una obra ajena con el propósito de presentarla como propia. Equivale a copiar, esto es, tomar algo de un lugar y reproducirlo en otro, borrando o cambiando el nombre del autor. Una mezcla de hurto y engaño, y seguramente también de autoengaño. Una decisión deliberada y plenamente consciente de apropiación ilegítima, in-

Correspondencia a: Dr. Ricardo López Pérez. E mail: ricardo.lopez@udp.cl - rlopezp@med.uchile.cl aceptable desde la perspectiva de la creatividad.

Para la percepción comiente existe una gran diferencia entre crear y copiar, como dos procesos muy distintos, aunque expresados con palabras que formalmente sólo cambian por apenas unas letras. Aun así, esta distinción es problemática desde el momento en que ningún mortal puede crear de la nada. Es preciso asumir, por tanto, que toda creación presupone la utilización de algo conocido, lo que determina cierto tipo de continuidad entre lo antiguo y lo nuevo. Con todo, la diferencia entre crear y copiar puede y debe ser establecida. 
Desde el punto de vista conceptual, precisamente, el hecho fundamental que permitió el uso de la palabra "creador" para referirse a los seres humanos, lo constituye el paso desde la creación como algo que surge de la nada (creatio ex nihilo), a la creación como un fenómeno que parte de lo existente. Eliminada esta condición que sólo podía cumplir Dios, los seres humanos se convierten en creadores, pero esta vez a partir de su mundo de experiencia. No se crea en el vacío ni con el vacío. El mismo Hermes, aun siendo inmortal, para fabricar la primera lira debió utilizar un caparazón de tortuga y unos restos de intestino de buey adaptados como cuerdas ${ }^{1}$.

Este hecho de apariencia obvia es medular, porque permite entender que la creatividad es una manera de utilizar provechosamente lo que está disponible. En el acto creativo siempre se encuentra un conjunto de recursos o hechos conocidos, pero proyectados en una nueva dimensión. Sin duda, crear tiene mucho de recrear. Los griegos del período clásico decían: "Había un Pilos antes de Pilos, y un Pilos aun anterior"2; y Nietzsche llegó a decir: "No es ser el primero en ver algo nuevo, sino en ver como si fuesen nuevas las cosas viejas y conocidas, vistas y revistas, lo que distingue a los cerebros verdaderamente originales" 3 .

Metafóricamente, muchos creadores representan esta situación. Por ejemplo, Pablo Picasso decía irónicamente que si había algo que robar, lo robaba"; Martha Graham a su vez afirmaba, "robo lo mejor donde quiera que esté (Platón, Picasso, Bertram, Ross), soy una ladrona y me honro de ello... pienso que conozco el valor de lo que robo y lo atesoro como una herencia y un legado"5; y el iconoclasta Marcel Duchamp suponía que, eligiendo algo perteneciente a un periodo anterior y adaptándolo al trabajo propio, se podían conseguir líneas creadoras ${ }^{6}$.

Otros autores han puesto el acento en el modo en que continuamente los hombres se sirven de la naturaleza. Demócrito, en el siglo V aC, afirmaba: "Los hombres son en las cosas más importantes discípulos de los animales: de la araña en el tejer y remendar; de la golondrina, para la construcción de viviendas; y en el canto, del cisne y del ruiseñor, todo ello por vía de imitación"7. La misma idea está expresada mucho después por Ralph Emerson: "El cuerpo humano es el depósito de las invenciones, la oficina de patentes en que están los modelos de los que se tomó cada sugestión" ${ }^{\prime \prime}$. Los testimonios son múltiples: los Cabiros, hijos de Hefesto, observaron a un cangrejo para fabricar las tenazas ${ }^{9}$; el más importante estadio de los Juegos Olímpicos de Beijing 2008, fue fabricado a imagen de un nido de pájaros; y la teoría de la tecnología de Marshall McLuhan sugiere que todas ellas son extensiones (copias) del cuerpo humano ${ }^{10}$.

Algo de esta problemática se manifiesta de singular manera en una pequeña historia asociada a Charles Chaplin. Cansado de tantos imitadores, resolvió demandar a uno de ellos, de apellido Amador, que había copiado su apariencia y sus rutinas; pero el hábil abogado que tomó su defensa logró demostrar que la indumentaria de Charlot no tenía nada de original, puesto que él mismo la había copiado: en 1899, un actor llamado George Beban utilizaba un bigote semejante; en 1892, un tal Harry Morris usaba unos inmensos zapatos; en 1898, el cómico Lenox salía a escena con un sombrero de hongo, y así sucesivamente $^{11}$. Charlot es el resultado de un largo proceso, al que contribuyen elementos habituales de la vida cotidiana, en eso tiene razón el abogado, pero sería muy injusto olvidar lo que Chaplin agrega. Este magnífico personaje corresponde a una inesperada articulación de elementos conocidos, es cierto, pero ahora con un sabor propio y en un ambiente de delicadeza y magia que no existían.

Con un tono de ironía, Voltaire afirmó en una oportunidad: "La originalidad no es más que una imitación inteligente"12. Alfred Whitehead llevó el argumento a su mayor tensión, al afirmar que toda la filosofía occidental no es más que un conjunto de anotaciones en los márgenes de los diálogos de Platón ${ }^{13}$. Así, con este criterio, muchos han negado, por ejemplo, el valor de los poetas trágicos, porque recogen una y cien veces los temas que siglos antes proponían Homero y Hesíodo, o la creatividad de las obras de Shakespeare, surgidas de muchas lecturas previas.

Este es el escenario en el que aparecen las acusaciones de plagio. La primera querella de este tipo se desata cuando Talos, sobrino del gran artesano Dédalo, toma casualmente una mandíbula de serpiente (otra versión dice un espinazo de pescado) y la utiliza para cortar una rama. Luego, 
habiendo advertido la potencia de su hallazgo, la reproduce en metal originando la primera sierra. Esta y otras invenciones le proporcionaron una gran reputación entre sus contemporáneos, excepto con su tío, quien afirmaba que el mérito de forjar la primera sierra le pertenecía. Dédalo resolvió la diferencia empujando a su sobrino desde lo alto de la Acrópolis ${ }^{14}$.

De allí en adelante, acusaciones semejantes se han multiplicado; algunas más celebres que otras. Newton y Leibniz se acusaron recíprocamente a propósito de la creación del cálculo infinitesimal, sin que sepamos a la fecha si fue efectivamente un plagio o un caso de descubrimiento simultáneo. Nada para sorprenderse, porque el mismísimo Descartes es sospechoso de plagiar las leyes de la refracción, relacionadas con el cambio de dirección de un rayo de luz al pasar de un medio a otro, formuladas por el matemático holandés Willebrord Snell ${ }^{15}$.

La publicación de la Encyclopédie, esa gigantesca obra ilustrada, aparece asociada a una acusación de plagio. El cura jesuita Berthier, escribió un artículo en el Journal de Trévoux, en el cual se afirma que la clasificación del conocimiento humano publicado en el Prospestus que precede a la Encyclopédie, está plagiado de una obra de Francis Bacon. Con prontitud Denis Diderot rechaza la acusación, alegando que el nombre del filósofo inglés se encuentra en las referencias ${ }^{16}$. Para mayor certeza, Jean D'Alambert agrega un apartado al Discurso Preliminar, centrado en la división de las ciencias de Bacon, en donde se lee: "No debe permitirse que se nos acuse de plagiarios ni siquiera sospechosos de tales"17.

Los hermanos Wright llegaron a los tribunales para evitar el plagio de su flamante máquina voladora. Sostuvieron una extensa batalla legal en contra de Glenn Curtiss, que recién en 1914, a once años del primer vuelo controlado y dos años después de la muerte de Wilbur Wright, dio por resultado una sentencia favorable en la Corte de Apelaciones de Dayton ${ }^{18}$.

En el último tiempo se han multiplicado las acusaciones de plagio contra el escritor peruano Alfredo Bryce Echenique. Recientemente la prensa de ese país informaba de un total de veintisiete acusaciones, todas ellas orientadas a denunciar la apropiación ilegítima de diversos textos, tomados especialmente de intelectuales españoles. La periodista chilena María Soledad de la Cerda documentó la existencia de dieciséis casos, entre los cuales se cuentan los plagios al periodista Juan Carlos Ponce y al escritor John Steinbeck. Junto con alegar que en algunos de éstos se trataría de errores lamentables, de responsabilidad de su secretaria, Bryce Echeniche avanzó también hacia una provocativa justificación: "El plagio es un homenaje"19. Esto es, al plagiar a un autor, al hacer desaparecer su nombre y de paso agregar el propio, se materializa realmente una especial muestra de respeto.

Chile no carece de célebres historias al respecto. Pablo de Rocka hizo público el plagio en que habría incurrido su enemigo literario y homónimo Pablo Neruda, al tomar el poema 30 de Rabindranath Tagore y convertirlo en su poema $16^{20}$. El primero de ellos dice: "Tú eres la nube del crepúsculo que flota en el cielo de mis sueños, te dibujo según los anhelos de mi amor, eres mía, mía y habitas en mis sueños infinitos". Y el segundo: "En mi cielo al crepúsculo eres como una nube y tu color y forma son como yo los quiero. Eres mía, eres mía, mujer de labios dulces y viven en tu vida mis infinitos sueños". Como sea, plagio o no, a partir de la tercera edición Neruda agregó un encabezado al poema en donde se lee: "Paráfrasis a R. Tagore"21.

Desde luego, la existencia de muchos casos de plagio, con diferentes matices y en distintas épocas, lugares y campos de actividad humana, no puede ser un consuelo ni una justificación. Ello sólo revela la complejidad del hecho y a su manera plantea un imperativo de claridad. No es deseable que la diferencia entre crear y copiar quede reducida a un valor cero, o que las relaciones entre creatividad y ética se den por descontadas.

El Gran Hacedor es el único creador que observa todo sin necesidad de mirar hacia atrás, ni asumir deudas en su producción creativa. El resto, simples mortales, trabajan invariablemente a partir de numerosos antecedentes previos, de modo que la continuidad $\mathrm{y}$, a ratos, la ruptura con alguna tradición no pueden exhibirse como factor que rebaja la creatividad, más bien debe entenderse que la respalda. Cualquier manifestación creativa pone a la vista la presencia de alguna mezcla, combinación o articulación entre elementos pre- 
viamente distanciados. En particular, la creatividad supone, y ciertamente exige, un activo diálogo entre fantasía y lógica.

Muchos grandes creadores han sido conscientes de este tipo de continuidad. Isaac Newton, considerado el científico más grande de la historia, llegó a decir: "Si pude ver más lejos que mis predecesores, fue porque ellos, gigantes de talla, me levantaron sobre sus hombros"22. Con esto en realidad sólo parafraseaba (tal vez plagiaba) al filósofo neoplatónico Bernardo de Chartes, quien en el siglo XII escribió: "Somos enanos encaramados en los hombros de gigantes. De esta manera vemos más y más lejos que ellos, no porque nuestra vista sea más aguda o nuestra estatura más alta, sino porque ellos nos sostienen en el aire y nos elevan con toda su altura gigantesca"23.

En este marco, se puede observar con algún detenimiento el caso de los poetas trágicos y el de Shakespeare.

El género trágico surgió a finales del siglo VI $\mathrm{aC}$, como un espectáculo de poderosas resonancias emocionales, combinando el canto, la música y la danza. Con la única excepción de Los Persas de Esquilo, que pone en escena la batalla naval de Salamina ocurrida ocho años antes, las restantes tragedias conservadas giran en torno a temas tomados principalmente de los relatos de Homero y Hesíodo. La tragedia obtiene sus contenidos de fuentes tradicionales, pero no simplemente para evocarlos, sino como un pretexto para debatir los asuntos propios de la polis; como la justicia, el poder, la guerra, el crimen, la culpa o el castigo. Tomar estos temas y proponerlos para enfocar situaciones nuevas, una crisis o un problema que exige solución, hacen de la tragedia un recurso para presentar los antiguos mitos desde una perspectiva ciudadana. Fuertemente vinculada a las preocupaciones de la polis, la tragedia marca una etapa en la formación del hombre cívico y del ciudadano responsable. No es sólo un fenómeno artístico, es también una institución política unida al curso de la democracia ${ }^{24}$.

El poeta Esquilo, por ejemplo, escribió una obra trágica dedicada a Prometeo, personaje de dos poemas de Hesíodo. Lo mismo respecto de la Orestíada, en donde se recrea la muerte de Agamenón a manos de su esposa Clitemnestra y su amante Egisto, asunto anticipado tres siglos antes por Homero. Ambos casos, sin embargo, están desarrollados en un formato y con una intención que no tienen relación con sus versiones originales. Prometeo deja de ser un astuto engañador de los dioses, de perfil soberbio, para convertirse en un héroe cultural, lúcido y autodeterminado. En tanto que el asesinato de Agamenón es ahora utilizado para plantear un asunto de la mayor importancia para el destino de la democracia, como es el paso de la venganza a la justicia.

Por su parte, Shakespeare escribió Hamlet a partir de una historia tradicional danesa que ya tenía dos versiones. La primera en el siglo XII, escrita en latín por Saxo Grammaticus y la siguiente por Francois de Bellesforest en el XVI. Esta obra cumbre de la creatividad literaria no surgió de la nada, sino de un relato tradicional. Shakespeare efectivamente recibió el asunto principal de su ambiente, pero eso no es todo, porque agregó escenas y personajes. Desde luego, incorporó el fantasma del padre de Hamlet, la llegada de los actores, la representación de una obra dentro de la obra para observar la reacción del rey Claudio, el asesino sospechoso, la escena entre Hamlet y su madre después de la representación, la locura de Ofelia y su suicidio por inmersión, los personajes Osric y Fortinbras, el papel de Laertes como vengador, el sepulturero y el funeral en el cementerio de la iglesia, entre otros elementos ${ }^{25}$. Sobre todo, convirtió a Hamlet en un personaje de insondable subjetividad, un verdadero paradigma de la indecisión envuelto en un mar de dudas, con la voluntad paralizada en medio de una confusa avalancha de pensamientos.

Todos los logros creativos arrancan de alguna realidad previa; del aporte de la cultura, de las generaciones anteriores, de aprendizajes que ni siquiera se recuerdan como tales. La cuestión crucial está en la posibilidad de ir más allá a partir de aquello que se ha recibido, descubierto o seleccionado. Crear y copiar son procesos muy distintos, sin duda, a condición de que aceptemos que la creatio ex nihilo está negada a los hombres y podamos observar cada creación en el contexto en que surge.

Con propiedad, esto último ha generado las condiciones para hablar de intertextualidad en conexión con los fenómenos creativos. Unos textos habitan en otros textos; todo el tiempo hay una relación, directa o sutil, de un texto actual con 
muchos otros anteriores, conocidos o no por el autor. Apunta a un fenómeno evidente de la creación intelectual, que de paso abre otra vertiente para el debate sobre las diferencias y los límites entre crear y copiar, pero ello no significa que la distinción se haya esfumado. De alguna manera éste es el contenido de la "ley fundamental de la Biblioteca" formulada por Jorge Luis Borges. Esta ley reconoce que todos los libros, sin excepción, tienen los mismos elementos: puntos, comas, espacios y, por cierto, las letras del alfabeto. Aun así, "no hay en la vasta Biblioteca, dos libros iguales"26.

Se puede crear hasta el infinito, sin necesidad de llegar al plagio, a la réplica astuta, a la copia mecánica. Margaret Boden, especialista en psicología cognitiva e inteligencia artificial, ha dicho: "Aun si supiésemos el contenido completo de la mente de alguien, la complicación derivada de sus poderes asociativos impediría una predicción detallada de sus pensamientos"27.

Así, una concepción en extremo purista anula la posibilidad de crear, porque nada podrá ser completamente original. Inversamente, una visión demasiado indiferente a los matices arroja todo a un campo de arbitrariedad. La fórmula parece estar en la capacidad para advertir que ni la originalidad ni la relevancia, propias de un resultado creativo, son criterios absolutos. La creatividad siempre implica un juicio, a la vez personal y social. Más aún, pone en juego algún sistema de preferencias; es expresión de un propósito, de una opción, en suma, es un gesto asociado a la libertad.

Al hilo de estas reflexiones, existe una certeza: la creación personal o colectiva supone llevar lo conocido más allá, elevarlo a otra dimensión, ponerlo en otro contexto, aplicarlo de nueva manera, en fin, proyectarlo de un modo parcialmente inédito. En modo alguno puede tratarse de una mera reproducción, de un movimiento vacío.

En el trabajo intelectual la originalidad nunca es absoluta; no puede serlo. Homero no fue plenamente original, no lo fue Platón, ni Freud, ni Heidegger. Al mismo tiempo, las ideas que nos brinda con generosidad la historia del pensamiento, de la filosofía, la ciencia o la literatura, están para ser usadas. Cumplen su mejor función cuando las personas las recogen, las discuten o bien las transforman; cuando son llevadas al dominio de la experiencia. Es preciso apropiarse de ellas y convertirlas en orientaciones para vivir, en criterios para razonar y para decidir. Son una vía de acceso al sentido del mundo privado y del mundo en que vivimos.

Hasta este punto no hay problema, pero una cosa distinta es recoger furtivamente un texto, borrar el nombre del autor y agregar el propio. Borges cuenta que sólo Pierre Menard pudo ser considerado autor del Quijote, sin que alguien tuviese autoridad para insinuar siquiera que se trataba de un saqueo. En este caso no cabe confundirse: "Su admirable ambición era producir unas páginas que coincidieran palabra por palabra y línea por línea con las de Miguel de Cervantes"28.

Ironías aparte y especialmente pensando en la universidad: ¿Qué ganancia se puede obtener cuando se desconoce, suaviza u oculta la existencia de un plagio, y todavía cuando se le procura una metafísica?

\section{REFERENCIAS}

1. Grimal P. Diccionario de Mitología Griega y Romana. Buenos Aires: Paidós. 2006.

2. Johnson P. Creadores. Buenos Aires: Vergara. 2007; 13.

3. López R. Prontuario de la Creatividad. (3a Edición). Santiago: Bravo y Allende. 2008; 90.

4. WaLteR I. Picasso. Colonia: Taschen. 1995.

5. GARDNER H. Mentes Creativas. Barcelona: Paidós. 1995; 322.

6. López R. Prontuario de la Creatividad. (3a Edición). Santiago: Bravo y Allende. 2008; 5.

7. Luanos A. Los Presocráticos y sus Fragmentos. Buenos Aires: Juarez. 1968; 241.

8. LóPEz R. Prontuario de la Creatividad. (3a Edición). Santiago: Bravo y Allende. 2008; 64.

9. Grimal P. Diccionario de Mitología Griega y Romana. Buenos Aires: Paidós. 2006.

10. Mcluhan M. El Medio es el Masaje. Buenos Aires: Paidós. 1969.

11. Vileggas López M. Charles Chaplin. El Genio del Cine. Barcelona: Folio. 2003; 207-8. 
12. López R. Prontuario de la Creatividad. (3a Edición). Santiago: Bravo y Allende. 2008; 225.

13. Whitehead A. Proceso y Realidad. Buenos Aires: Losada. 1956.

14. Graves R. Los Mitos Griegos. Buenos Aires: Ariel. 2007; 102-3.

15. Alégre C. Un Poco de Ciencia Para Todo el Mundo. Barcelona: Paidós. 2005; 44 y 63.

16. Bцом P. Encyclopédie. Barcelona: Anagrama. 2007; $121-2$.

17. D’Alembert J. Discurso Preliminar de la Enciclopedia. Madrid: Aguilar. 1985; 181.

18. Toвin J. Los Hermanos Wright. Buenos Aires: El Ateneo. 2003; 425.

19. www.latercera.cl. Martes 8 de abril de 2008 (Acc. 08/2008).

20. www.sandovalsignpost.com (Acc. 08/2008).
21. Neruda P. Obras Completas. Buenos Aires: Losada. 1967; 1; 98.

22. López, R. Prontuario de la Creatividad. (3를 Edición). Santiago: Bravo y Allende. 2008; 58.

23. Le Goff J. Los Intelectuales en la Edad Media. Barcelona: Gedisa. 1996; 31.

24. Vernant JP, Vidal-Naquet P. Mito y Tragedia en la Antigua Grecia. Barcelona: Paidós. 2002; 1: 33.

25. Johnson P. Creadores. Buenos Aires: Vergara. 2007; 99.

26. Borges JL. La Biblioteca de Babel. En Ficciones. Buenos Aires: Emecé. 1971; 89.

27. Boden M. La Mente Creativa. Barcelona: Gedisa. 1994; 313.

28. Borges JL. Pierre Menard, Autor del Quijote. En Ficciones. Buenos Aires: Emecé. 1971; 49-50. 